\title{
Modelling of a Wind Turbine with Permanent Magnet Synchronous Generator
}

\author{
E. N. López-Ortiz, D. Campos-Gaona, E.L. Moreno-Goytia \\ Instituto Tecnológico de Morelia \\ Morelia, México \\ nabriel_17@yahoo.com.mx, davidcg@ieee.org, elmg@ieee.org
}

\begin{abstract}
This investigation presents the implementation and simulation of a Simulink-based controlled permanent magnet synchronous generator (PMSG) wind turbine in the dq0 reference frame. The model consists of a current control subsystem, a PMSG model, a mechanical subsystem, a pitch angle controller and a wind turbine model. The current control subsystem makes use of PI controllers governing the wind turbine speed, the direct and quadrature stator currents and the pitch angle of the turbine blades. The pitch angle controller measures the speed and the active power from the generator limiting both in case of high-speed wind conditions. In order to verify the functioning and the effectiveness of the proposed controllers, simulations- for different operation conditions- are presented and discussed.
\end{abstract}

Keywords - Permanent magnet synchronous generator, Wind Turbine, Control, Modeling.

\section{INTRODUCTION}

Throughout history the use of wind energy has been a constant for human kind. Such energy comes from a renewable source, namely, the natural and continuous atmospheric processes [1]. The use of wind energy has increase notably in recent years, especially for generation of electric power [2]. This is because the increasing need of finding less polluting alternatives for energy production has found in wind power system a realizable option, with the power-electronic controlled variable speed wind turbines as the most efficient scheme. The speed and the pitch angle of the blades of these turbines are controlled by digital algorithms in all time [3].

One of the problems associated with variable-speed wind systems today is the presence of the gearbox coupling the wind turbine (WT) to the generator, which have proven to require maintenance constantly and replacement well before its design life [4][5]. To improve reliability of the WT and reduce maintenance expenses the gearbox should be eliminated [6]. Because of this need, direct drive variable speed wind turbines based on multi-pole permanent magnet synchronous generator (PMSG) with full-scale converter, have began to gain acceptance among wind turbine developers such as Vestas, GE Wind, Goldwind, Siemens and Gamesa, specially for offshore wind farm developments. The advantages of using variable-speed with PMSG, are: better reliability, longer life and improved performance [7] however, since the blades of a PMSG WT are direct-coupled to the generator, the speed of its rotor (i.e. 5-25 rpm) is much more slower than the gearbox generators (which is around $1500 \mathrm{rpm}$ ), this conveys the need of higher torque in the PMSG to produce the same amount of power of a gearbox generator, which is translated in larger rotor diameters (around 7 times) to sustain the tangential stress produced by the increased torque [7].

This investigation presents the model of a PMSG WT able to work under low and fast wind speed conditions and during wind gusts. The PMSG has the benefits of high power density, low losses, no need of gearbox, and the characteristic of not requiring a rotor field excitation. The modeling and simulations are carried out using Simulink with a sample time of $50 \mathrm{e}-6 \mathrm{sec}$.

\section{MOdELING OF THE PMSG WT}

\section{A. Current Controller}

The control of the $i_{d}$ and $i_{q}$ stator currents are carried out indirectly by controlling the $d$ and $q$ voltages of the machine, where [8]:

$$
\begin{gathered}
L_{d} \frac{d i_{d}}{d t}+R_{s} i_{d}=u_{d} \\
L_{q} \frac{d i_{q}}{d t}+R_{s} i_{q}=u_{q}
\end{gathered}
$$

where $L_{d}, L_{q}, i_{d}, i_{q}, u_{d}$ and $u_{q}$ are the $d$ and $q$ components of the stator inductances currents and voltages respectively and $R_{s}$ is the stator resistance.

The current control makes use of the compensators $K_{d}$ and $K_{q}$ for $i_{d}$ and $i_{q}$ respectively. The $i_{d}$ compensator obtains the error signal $e_{d}=i_{d r e f}-i_{d}$ and commands the injection of a 
control voltage $u_{d}$. In a similar way, the $i_{d}$ compensator obtains the error signal $e_{q}=i_{\text {qref }}-i_{q}$ and commands the injection of a control voltage of $u_{q}$. Assuming that the transfer function of the closed-loop systems $I_{d} / I_{d r e f}$ and $I_{q} / I_{\text {qref }}$ are first-order with a time constant of $\tau_{i}$ then $K_{d}$ and $K_{q}$ are defined, using the Laplace operator $s$, as:

$$
\begin{gathered}
K_{d}=\frac{L_{d} s+R_{s}}{\tau_{i} s} \\
K_{q}=\frac{L_{q} s+R_{s}}{\tau_{i} s}
\end{gathered}
$$

Fig. 1 shows a block diagram of the current control subsystem, where $P=1 / \mathrm{s}$.

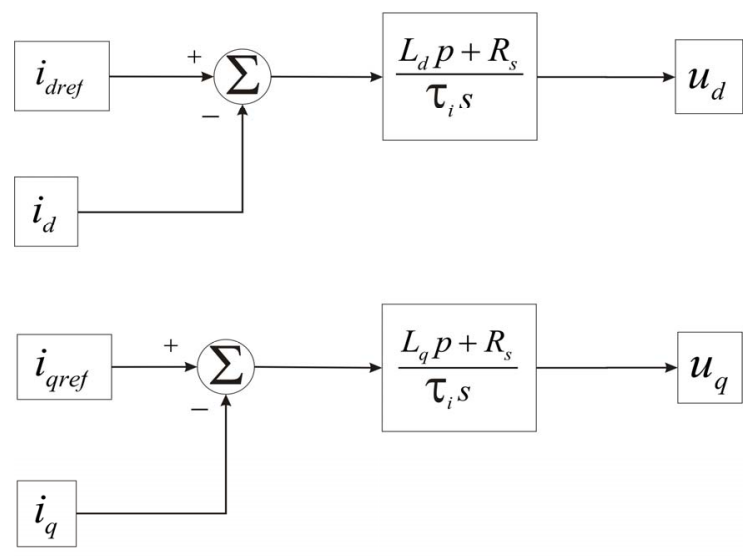

Figure 1. $d$ and $q$ current controllers

\section{B. Modeling of the permanent magnet synchronous generator}

The dynamic model of the PMSG is carried out using the synchronous $d q$ reference frame, where the dynamic behavior of the PMSG currents can be defined as [9]:

$$
\begin{gathered}
\frac{d i_{d}}{d t}=-\frac{R_{a}}{L_{d}} i_{d}+\omega_{e} \frac{L_{q}}{L_{d}} i_{q}+\frac{1}{L_{d}} u_{d} \\
\frac{d i_{q}}{d t}=-\frac{R_{a}}{L_{q}} i_{q}-\omega_{e}\left(\frac{L_{d}}{L_{q}} i_{d}+\frac{1}{L_{q}} \lambda_{0}\right)+\frac{1}{L_{q}} u_{q}
\end{gathered}
$$

where, $u_{d}, u_{q}, i_{d}$ and $i_{q}$ are the $d$ and $q$ components of the stator voltage and current respectively, $R_{a}$ is the armature resistance, $\omega_{e}$ is the electrical rotor speed (which is related to the mechanical speed, $\omega_{g}$, as $\omega_{e}=n_{p} \omega_{g}$ with $n_{p}$ as the pole pairs), and $\lambda_{0}$ is the flux of the permanent magnet. The electrical frequency is given by $f_{e}=\omega_{e} / 2 \pi$, the inductances
$L_{d}$ and $L_{q}$ are the sum of the generator inductances in the $d$ and $q$ axes.

The $q$ axis current counterbalance the electrical potential $e_{q}=\omega_{e} \lambda_{0}$, and the $\mathrm{d}$ axis current counterbalance the electrical potential $e_{d}=0$. Assuming that $L_{d}=L_{q}=L$ then (3a) and (3b) can be written as:

$$
\begin{gathered}
\frac{d i_{d}}{d t}=-\frac{R_{a}}{L} i_{d}+\omega_{e} i_{q}+\frac{1}{L} u_{d} \\
\frac{d i_{q}}{d t}=-\frac{R_{a}}{L} i_{q}-\omega_{e}\left(i_{d}+\frac{1}{L} \lambda_{0}\right)+\frac{1}{L} u_{q}
\end{gathered}
$$

Fig. 2 shows a block diagram of the PMSG model based in (4a) and (4b), where $P=1 / s$. Past model requires the rotor speed (which is obtained from the mechanical system) and the voltages coming from the current controllers.

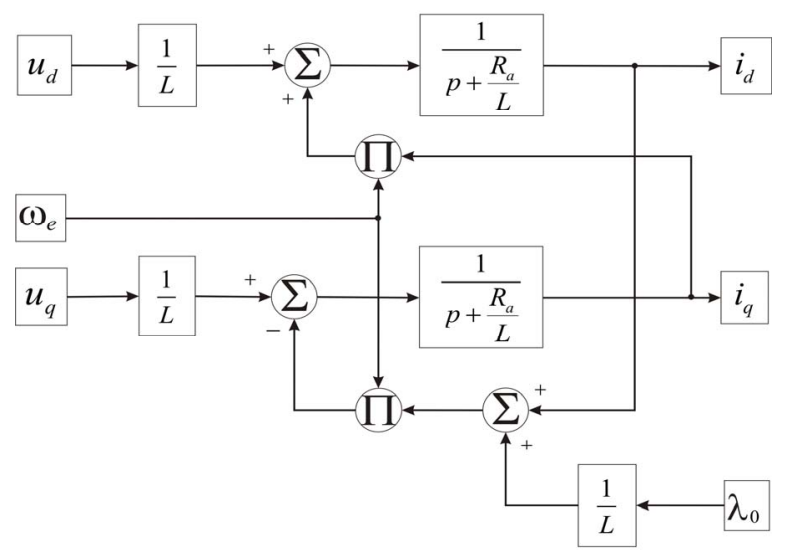

Figure 2. PMSG model

\section{Modeling of the mechanical system}

The model of the mechanical system uses the PMSG currents as an input variable and provides as outputs the rotor speed and the electromagnetic torque of the PMSG.

The electromagnetic torque, $T_{e}$, is calculated using [10]:

$$
T_{e}=\left(\frac{3}{2}\right)\left(\frac{n_{p}}{2}\right)\left[\left(L_{d}-L_{q}\right) i_{d} i_{q}+i_{q} \lambda_{0}\right]
$$

If $L_{d}-L_{q}$ is stated as $L_{d q}$, then $T_{e}$ can be stated as:

$$
T_{e}=(0.75) n_{p} i_{q}\left(L_{d q} i_{d}+\lambda_{0}\right)
$$

Using (6) the dynamics of the generator speed $\omega_{g}$ can be stated as:

$$
\frac{d \omega_{g}}{d t}=\left(T_{e}-T_{\omega, g}-B_{m} \omega_{g}\right) / J_{e q}
$$


where the sub index $g$ represents the generator parameters, $J_{e q}$ is the moment of inertia of the WT, (where $J_{e q}=J_{g}+J_{\omega} / n_{g}{ }^{2}$ with $n_{g}$ is the gearbox ratio) $B_{m}$ is the damping coefficient of the turbine, $T_{\omega, g}$ is the aerodynamic torque (defined as: $T_{\omega, g}=T_{\omega} / n_{g}$ ) and $\omega_{g}$ is the mechanical speed of the generator.

Fig. 3 shows the block diagram of the mechanical system based on (6) and (7). The model requires as an input, the mechanical torque extracted from the wind, as seen in Fig. 3.

\section{Modeling of the speed controller}

Fig. 4 shows the speed controller of the WT. Such controller sets the $q$-current reference by using a PI. The proportional constant of the controller is $K_{p \omega}$ and the integral constant is $K_{i \omega}$.

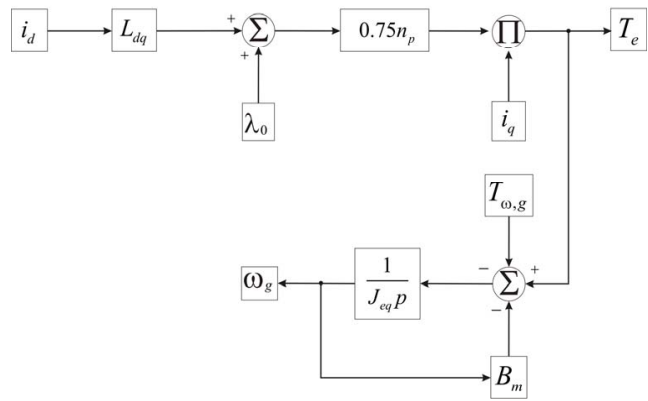

Figure 3. Schematic diagram of the mechanical system

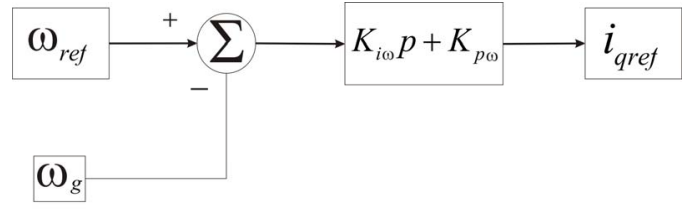

Figure 4. Schematic diagram of the speed controller

\section{E. Modeling of the pitch angle controller}

The pitch angle controller modifies the power coefficient $(C p)$ of the turbine which in turn affects the active power produced by the WT. Under low wind speed conditions, the pitch angle control is seldom activated; instead it remains fixed for an optimum value of $C p$. Under high wind speed conditions the pitch angle controller limits the amount of energy extracted from the wind avoiding the overload of the PMSG. A schematic of the pitch angle controller is shown in Fig. 5.

This controller requires as an input the actual active power, $P e$, generated, which is calculated as:

$$
P e=\left(i_{d} u_{d}\right)+\left(i_{q} u_{q}\right)
$$

where $u d$ and $u q$ are the $d q$ voltages coming from the current control model, $i d$ and $i q$ are the $d q$ currents of the PMSG. The active power calculation subsystem is shown in Fig. 6.
The pitch angle controller uses the nominal wind speed $\omega_{\text {wnom }}$ variable and the nominal active power reference Peref variable to the wind speed and active power values that will activate the pitch angle controller. A higher than nominal wind speed modifies the angle $\theta$ of the blades, the higher the winds the larger $\theta$ must become. Because of the past, the block MAX used in the diagram makes sure that the current winds peed is larger than $\omega_{\text {wnom }}$ before activating the pitch angle controller.

\section{F. Wind turbine Model}

The wind turbine model is taken from the Simulink SimPower Systems library. Such model requires the input variables wind speed, pitch angle and rotor speed to be in PU quantities, because of that, the block convPU is used to turn the input variables in PU. The mechanical torque produced by the wind turbine model is also given in PU so a block named convSI is used to convert the PU quantities to SI values. A schematic diagram of the wind turbine subsystem is shown in Fig. 7.

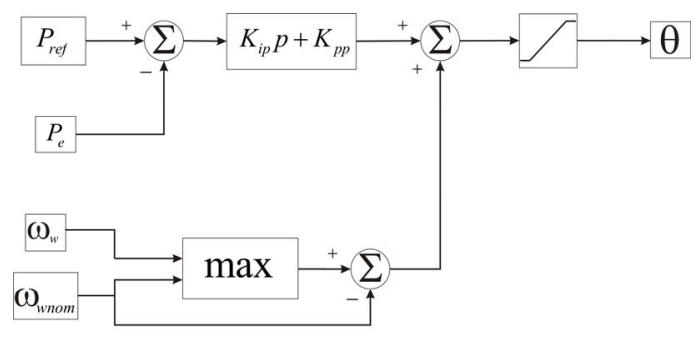

Figure 5. Schematic diagram of the pitch angle controller

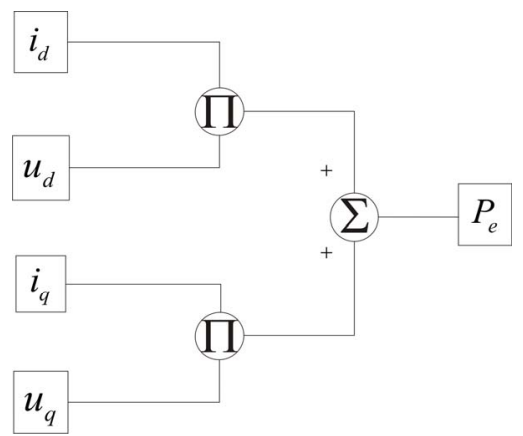

Figure 6 . The active power calculation subsystem

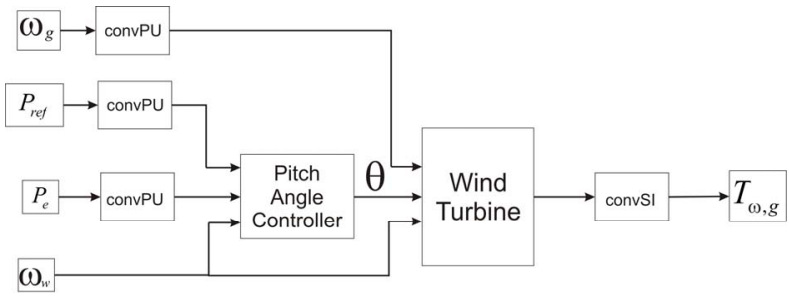

Figure 7. Schematic diagram of the wind turbine subsystem

\section{G. Full model integration}

The subsystems previously presented are interconnected to realize the full model of the WT as shown in Fig. 8. 


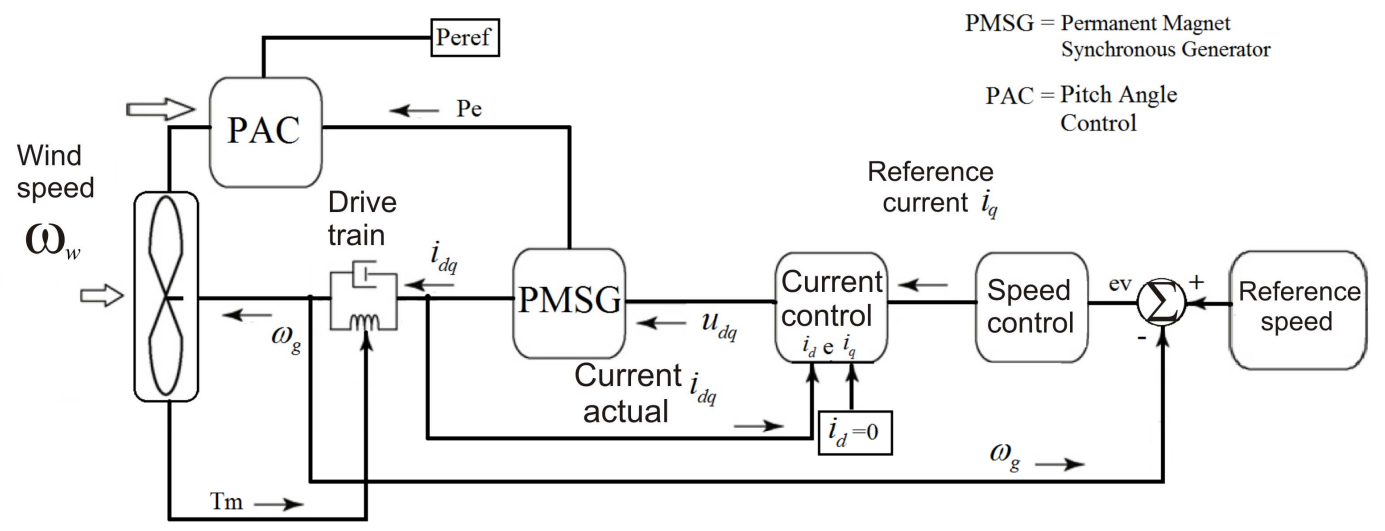

Figure 8. Schematic diagram of PMSG WT model

The generator speed controller in Fig. 8 requires has an input the difference between the reference and the actual generator speed and provides the $i_{q}$ required by the current controller. The current controller also requires a $i_{d}$ reference which is usually set to zero. The PMSG model uses the voltages produced by the current controllers to generate the real $d q$ currents of the machine, which in turn are used to calculate $T_{e}$ inside the mechanical subsystem. The $T_{e}$ produced by the PMSG, along with the $T_{\omega, g}$ produced by the turbine are used to determine $\omega_{g}$, which finally is fed to the speed controller.

\section{SIMULATIONS}

In order to evaluate the performance of the developed model, several simulations in both steady state and transient operation conditions are carried out. The parameters of the model are considered to be constant and time-invariant.

\section{A. Change of rotor speed reference value}

On this simulation, the $\omega_{g}$ reference of the controller is changed from $100 \mathrm{rad} / \mathrm{s}$ to $130 \mathrm{rad} / \mathrm{s}$ in the second 20. Fig. 9 shows the behavior of the PMSG rotor speed during the change of rotor speed reference value.

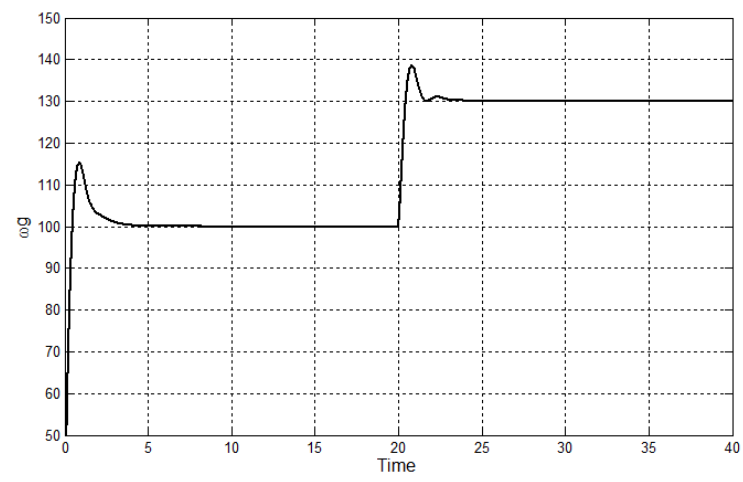

Figure 9. Generator speed behavior during a generator speed reference variation
The change of the rotor speed reference value does not have an effect in the pitch angle of the turbine blades because the wind speed remained in a value below the activation level of the pitch angle controller during the simulation time. The behavior of $T_{e}, T_{m}, u d, u q, i_{q}$ and $i_{\text {qref }}$ are shown in Figs. 1012.

\section{B. Wind speed variation}

In order to test the performance of the pitch angle controller, on this simulation the wind speed is changed from $10 \mathrm{~m} / \mathrm{s}$ to $14 \mathrm{~m} / \mathrm{s}$ at the second 15 and from $14 \mathrm{~m} / \mathrm{s}$ to $13 \mathrm{~m} / \mathrm{s}$ at second 30 as shown in Fig. 13. The rotor speed reference is kept constant at $150 \mathrm{rad} / \mathrm{s}$ during the simulation.
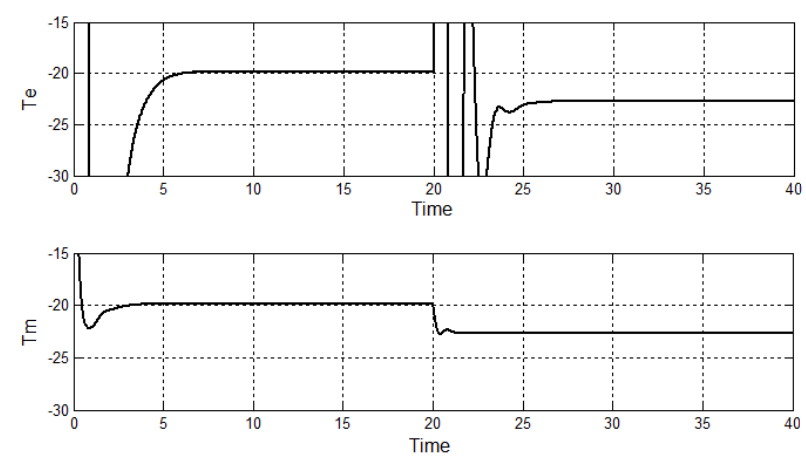

Figure 10. Electric and mechanical torque behavior during a generator speed reference variation
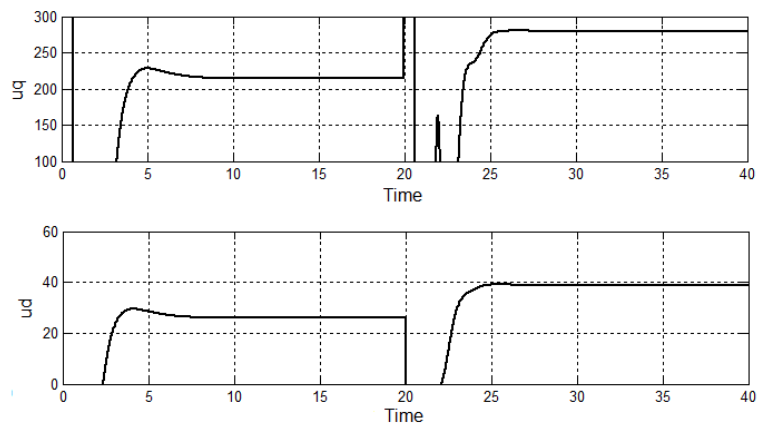

Figure 11. dq voltages behavior during a generator speed reference variation 

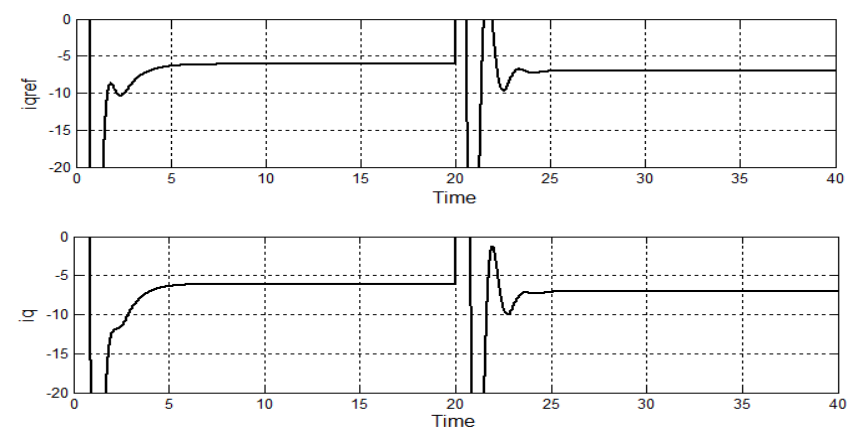

Figure 12. iqref and iq behavior during a generator speed reference variation

As seen in Fig. 14, the angle $\theta$ changes from a zero value when the wind speed exceeds the nominal wind speed value of the pitch angle controller, in this way the PMSG is protected from higher-than-nominal $T_{m}$ product of the high wind speeds. Because of the past, $\omega_{g}$ remains constant during the wind gust, following its reference. The behavior of $T_{e}, T_{m}, u d, u q, i_{q}$ and $i_{q r e f}$ are shown in Figs. 15-17.
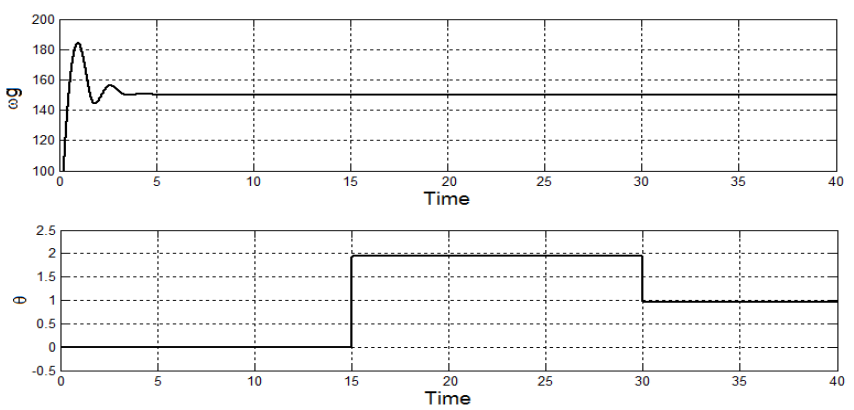

Figure 14. Generator speed and angle $\theta$ behavior during wind speed variations

\section{CONCLUSION}

The results presented show that the speed and the pitch angle controller of the PMSG developed in this investigation produce satisfactory control actions and can be used to control a PMSG WT. The excessive power generated by the wind gusts was effectively balanced by the controllers, avoiding the overload of the generator. The time constants of the PI controllers must be chosen in order to avoid excessive control actions and unwanted current peaks, balancing between speed of response and the overshot of the control signals.
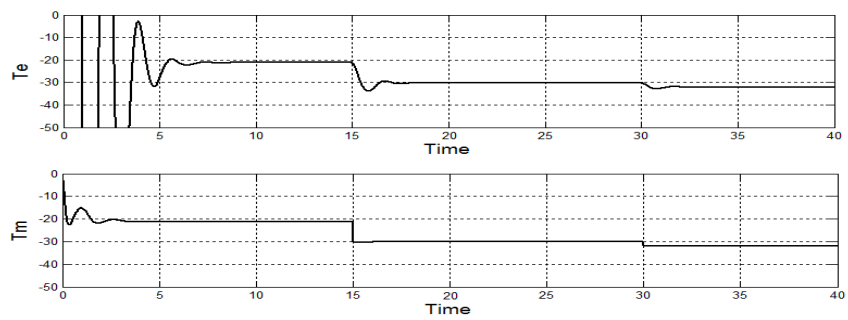

Figure 15. Electric and mechanical torque behavior during wind speed variations
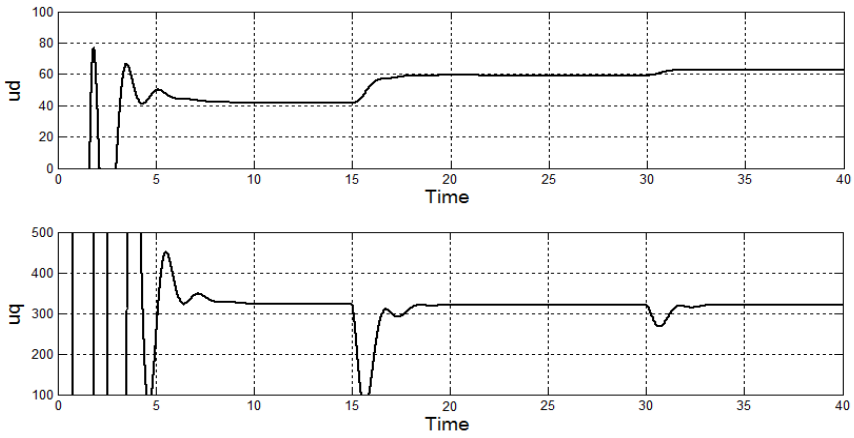

Figure 16. dq voltages behavior during wind speed variations
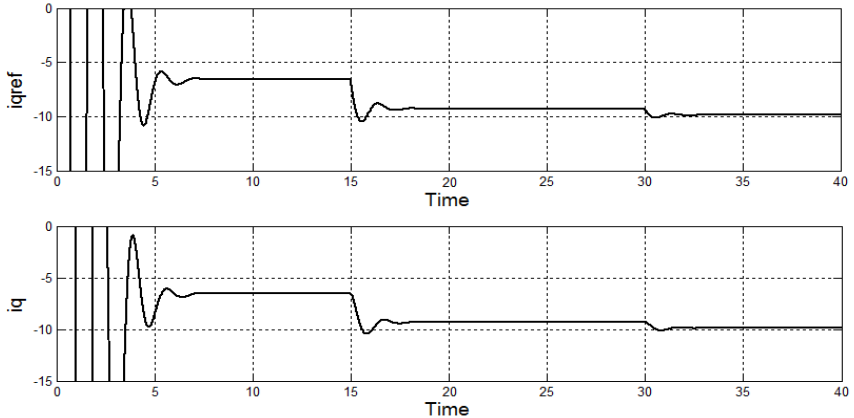

Figure 17. iqref and iq behavior during wind speed variations

\section{APPENDIX}

The parameters of the PMSG used in the paper are listed below:

Rated power: $6000 \mathrm{~W}$

Generator reference speed: $153 \mathrm{rad} / \mathrm{s}$

Rated electrical torque: 40 N.m

Permanent magnet flux: $0.433 \mathrm{~Wb}$

Number of pole pairs: 10

Rotational damping: 0

Equivalent inertia: $7.856 \mathrm{Kg} . \mathrm{m}^{2}$

Inductance: $8.5 \times 10^{-3} \mathrm{H}$

Armature resistance: $0.425 \Omega$

Synchronous resistance: $0.45 \Omega$

The parameters for the Control are:

$K_{p \omega}=10$

$K_{i \omega}=10$

$K_{p p}=0.1$

$K_{i p}=1000$

\section{REFERENCES}

[1] Billinton, R.; Guang Bai; "Generating capacity adequacy associated with wind energy," Energy Conversion, IEEE Transactions on , vol.19, no.3, pp. 641- 646, Sept. 2004.

[2] Gilbert M. Masters, "Renewable and efficient electric power systems", New Jersey, John Wiley \& Sons Inc, 2004.

[3] Ki-Hong Kim, Yoon-Cheul Jeung, Dong-Choon Lee, and Heung-Geun Kim, "Robust Control of PMSG Wind Turbine Systems with Back-to- 
Back PWM Converters", 2nd IEEE International Symposium on Power Electronics for Distributed Systems, 2010.

[4] Musial, W., Butterfield, S., McNiff, B.: 'Improving wind turbine gearbox reliability'. European Wind Energy Conf. (EWEC 2007), 2007

[5] Tavner, P., Xiang, J., Spinato, F.: 'Reliability analysis for wind turbines', Wind Energy, 2007, 10, pp. 1-18

[6] Semken, R.S.; Polikarpova, M.; Ro ytta , P.; Alexandrova, J.; Pyrho nen, J.; Nerg, J.; Mikkola, A.; Backman, J.; , "Direct-drive permanent magnet generators for high-power wind turbines: benefits and limiting factors," Renewable Power Generation, IET , vol.6, no.1, pp.1-8, January 2012

[7] Hong-Woo Kim, Sung-Soo Kim, Hee-Sang Ko, "Modeling and control of PMSG-based variable-speed wind turbine" Electric Power Systems Research volume 80, issue 1, pp. 46-52, January 2010.

[8] A. Yazdani, R. Iravani, "Voltage-sourced converters in power systems. Modeling, control and applications", New Jersey, John Wiley \& Sons Inc, 2010.

[9] Ming Yin; Gengyin Li; Ming Zhou; Chengyong Zhao;, "Modeling of the Wind Turbine with a Permanent Magnet Synchronous Generator for Integration," Power Engineering Society General Meeting, 2007. IEEE , vol., no., pp.1-6, 24-28 June 2007

[10] Tan, K.; Islam, S.; "Optimum control strategies in energy conversion of PMSG wind turbine system without mechanical sensors," Energy Conversion, IEEE Transactions on , vol.19, no.2, pp. 392- 399, June 2004 